\title{
DESVENTURAS DO TRABALHO NA PÓS-GRADUAÇÃO: UMA ANÁLISE DISCURSIVA DE COMENTÁRIOS NUM GRUPO DE BOLSISTAS NO FACEBOOK
}

\author{
Francisco Vieira da Silva \\ E-mail: francisco.vieiras@ufersa.edu.br \\ Universidade Federal do Semi-Árido (UFERSA) \\ DOI: 10.15628/rbept.2020.11166
}

Artigo submetido em: set/2020 e aceito em: nov/2020

\begin{abstract}
RESUMO
O enfoque deste estudo reside em analisar discursivamente, a partir de comentários publicados num grupo de bolsistas de uma agência de fomento no Facebook, como se constrói representações acerca do trabalho na pós-graduação na atualidade, a partir de relações de saber-poder. Para isso, analisam-se dez comentários publicados numa postagem que circulou no grupo destacado no mês de agosto de 2020. O aparato teórico que norteia a investigação repousa na perspectiva dos estudos discursivos de Michel Foucault. O estudo aponta a recorrência de posicionamentos discursivos fundidos em saberes a defender a improdutividade do tempo dispendido à pós-graduação e a ausência de um retorno financeiro compatível com o esforço demandado.
\end{abstract}

Palavras-chave: Discurso. Trabalho. Pós-Graduação.

\section{MISADVENTURES OF WORK IN POSTGRADUATE COURSE: A DISOURSIVE ANALYSIS OF COMMENTS IN GROUP OF SCHOLARSHIPS ON FACEBOOK}

\begin{abstract}
The focus of this study is to analyze discursively, from comments published in a group of scholarship holders from a development agency on Facebook, how to build representations about the work in postgraduate course are constructed today, from relationships from knowledge-power. For this reason, ten comments published in a post that circulated in the highlighted group on August 2020 are analyzed. The theoretical apparatus that guides the investigation rests in the perspective of Michel Foucault's discursive studies. The study points to the recurrence of discursive positions merged on knowledge defending the unproductively of time spent on graduate studies and the absence of a financial return compatible with the effort required.
\end{abstract}

Keywords: Discourse. work. Postgraduate course.

\section{INTRODUÇÃO}

A gênese da pós-graduação brasileira esteve vinculada de maneira tenaz à necessidade de formar quadros de alto nível que pudesse elevar o status da produção industrial brasileira, após a Segunda Guerra Mundial, 
quando os países deram conta de que a produção especializada do conhecimento criava condições de desenvolvimento social e econômico, principalmente a partir da exploração das potencialidades naturais de cada nação. De acordo com Nascimento (2018), as principais agências de fomento à formação de quadros de nível superior foram criadas no começo dos anos de 1950. Assim, tanto o Conselho Nacional de Pesquisa (CNPQ), como a Coordenação de Aperfeiçoamento de Pessoal de Nível Superior (CAPES), surgiram em 1951, a partir de pressões da Sociedade Brasileira para o Progresso da Ciência (SBPC), fundada em 1948. Em meados da década 1960, são criados os Planos Nacionais de Desenvolvimento da Pós-Graduação (PNPGs) e esse nível educacional entra em franca expansão. Ainda nessa década, a inserção da pós-graduação na Lei de Diretrizes e Bases da Educação Nacional (LDB) é responsável por enxertar essa etapa de ensino no raio das políticas de Estado e nas reformas educacionais por que passou a educação superior no país. Conforme frisam Kipnis e Carvalho (2006, p. 56), "[...] a pós-graduação, no Brasil, no que diz respeito a programas stricto sensu, pode ser considerada como exemplo de políticas públicas governamentais de longo prazo".

$\mathrm{Na}$ percepção de Freitas e Souza (2018), as configurações dos PNPGs, dos anos de 1960 até a contemporaneidade, permitem-nos radiografar as mutações da pós-graduação, através de reformas conjugadas por forças políticas e econômicas. Seguindo a perspectiva das autoras, vemos que o primeiro PNPG (1975-1979) foi emoldurado no âmbito do regime militar e tinha como objetivo "formar especialistas no âmbito da docência, pesquisa e atuação técnica também para atuar no parque industrial brasileiro". (FREITAS; SOUZA, 2018, p. 128). Aliado ao que afirmamos no parágrafo anterior, a formação de um corpo técnico nacional atrelou-se às aspirações de cunho desenvolvimentista, acentuados pelo ufanismo da ditadura militar. Já o segundo PNPG (1982-1985), consoante Freitas e Souza (2018), ocorre no período da chamada redemocratização e priorizou a necessidade de fortalecer a qualidade da produção científica brasileira. O terceiro PNPG (1986-1989) revelou uma série de prejuízos a partir de um cenário de incertezas socioeconômicas, as quais afetaram a destinação e captação de recursos pelas universidades.

Seguindo ainda a leitura de Freitas e Sousa (2018), entendemos que o III PNPG (1986-1989) perpassa o período em que se elaborou e promulgou a Constituição de 1988. Nesse período, ainda que haja avanços a partir desse dispositivo normativo, a situação econômica do Brasil afetou sobremaneira o desenvolvimento das pesquisas acadêmicas. Registre-se ainda que o país vivenciou no final dos anos de 1980 e no começo da década seguinte um período de intensa crise fiscal, caraterizada, notadamente, pelo malogro de uma série de planos econômicos. O IV PNGP não foi oficializado, ainda que, em 1996, tenha sido realizado um seminário que visou a discutir as diretrizes e normas para um quarto plano. Conforme Ribeiro (2016) e Freitas e Sousa 
(2018), o fato de esse documento nunca ter sido tornado público possibilito que alguns estudiosos não o considerem como um quarto PNPG. No entanto, o V PNPG (2005-2010) leva em conta a existência de um PNPG anterior, apesar de não haver a sua circulação pública, as ações que orientaram a Capes, no período de 1996 a 2004, seguiram certos princípios específicos.

Nessa ótica, o quinto PNPG reitera a relação entre a pesquisa científica e o mercado de trabalho, de modo que determinadas áreas do saber são tidas como prioritárias. De acordo com Ribeiro (2016, p. 47), "[...] fica claro no V PNPG ações que vinham sendo delineadas desde o I PNPG no sentido de privilegiar algumas áreas do saber em detrimentos de outras". O VI PNPG (2011-2020) encontra-se articulado ao Plano Nacional de Educação (PNE) e reforça as articulações entre a pesquisa e o setor privado, o desenvolvimento da tecnologia vinculada aos interesses do mercado, na batida neoliberal que dá as cartas na contemporaneidade. Para isso, a avaliação dos programas ocorre por meio da produtividade acadêmica, medida, principalmente, pela quantidade de produção bibliográfica de docentes e discentes. De acordo com um relatório publicado pela Comissão de Acompanhamento do PNPG (20112020), em 2019, urge a necessidade de aprimorar o modelo de avaliação dos cursos de pós-graduação que englobe o aspecto multidimensional por meio dos seguintes itens: formação de pessoal, pesquisa, inovação e transferência de conhecimento, impacto na sociedade e internacionalização.

A ênfase na relação entre a pesquisa e o mercado aparece reiteradas vezes no decorrer do documento, por meio de menções a "estágios de discentes em empresas", "empresas e seus processos de inovação", "gerações de novos negócios", "startups", "spin offs acadêmicos, dentre outros termos. Não estamos aqui defendendo que tais parcerias não sejam relevantes, tanto do ponto de vista acadêmico quanto social e, principalmente, se pensarmos numa certa retroalimentação da produção científica com o desenvolvimento econômico; todavia, faz-necessário problematizar que nem todas as áreas do saber matizam-se por esse impacto direto no mercado e que, por isso, não devem ser reguladas por mecanismos de controle que se mostram homogeneizantes.

Em suma, os planos destacados permitem-nos perceber as transformações sofridas pela pós-graduação, bem como a permanência de determinadas tendências, como a constante alegação de que a pesquisa precisa se incorporar ao setor produtivo (RIBEIRO, 2016). O que mudou, por outro lado, foi o inconteste avanço desse nível educacional em todo o país. Para o relatório da Comissão de Acompanhamento do PNPG (2011-2020), o aumento pode ser visto no número de tese e dissertações, bem como na qualificação da produção acadêmica, parametrizada pelo impacto das publicações. O documento aponta que o Brasil, em 1998, de acordo com o Web of Science Group, ocupava o $20^{\circ}$ lugar no ranking mundial, enquanto em 2018, passou a figurar na $13^{\circ}$ posição, com mais de 65 mil artigos publicados. 
Ainda que o país ainda não apresente um índice de citação dos artigos tão alto,

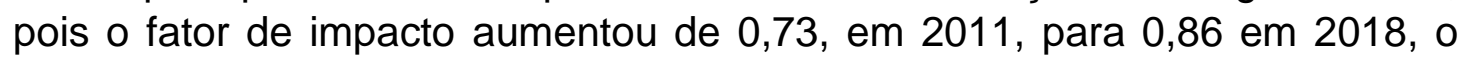
expressivo aumento no número de alunos matriculados em programas de pósgraduação stricto sensu, a existência de mais programas, bem o quantitativo de titulados e de discentes bolsistas mostra uma evolução flagrante de formação de quadro superior e, com isso, o acréscimo da produção acadêmica.

Um estudo realizado por Lopes (2019), na Consultoria Legislativa da Câmara dos Deputados, revelou que entre 2004 e 2017, o aumento no número de alunos matriculados na pós-graduação passou de 143.299 para 324.087 , o que representa uma ampliação de cerca de 126,16\%. Já entre 2000 e 2017, o número de mestres titulados no país cresceu $215 \%$ e o quantitativo de doutores chegou a um alargamento de $306 \%$. Com isso, a participação brasileira na produção da ciência mundial saltou de 1,30\% para 2,94\% em menos de vinte anos. Ainda que haja uma certa assimetria entre as instituições de ensino e as regiões do país, o fato é que a expansão da rede federal do ensino alcançou lugares antes desassistido e isso representa um marco importante na redução das desigualdades socioeconômicas e regionais.

No entanto, é mister destacar que, especialmente nos últimos cinco anos, as turbulências que afetaram a cena política brasileira podem inibir os avanços do país no campo científico. Antes mesmo do impeachment da presidenta Dilma Rousseff, o Brasil já havia reduzido acentuadamente os investimentos em ciência e tecnologia e, após a vitória de um candidato de extrema direita, no pleito de 2018 , os abalos produzidos são ainda mais preocupantes, a partir da elevação do negacionismo científico como uma pauta do governo. Vivemos nos dias de hoje a catástrofe de uma crise sanitária sem precedentes na história recente do mundo, recrudescida por visões distorcidas do governo acerca do vírus que causa a Covid-19, a minimização dos impactos da doença e o desprezo ao saber científico em prol de convicções pessoais e teorias da conspiração. Junte-se a isso o permanente corte de investimentos e de bolsas de pesquisa que, ainda com valores irrisórios, custeiam a permanência de diversos pesquisadores em vários lugares do país. Num momento em que se exige a pressa por uma vacina contra a Covid-19, assistese ao desmonte da ciência e da tecnologia e ao desencanto de diversos pesquisadores com os rumos da pesquisa nacional.

Nesse clima, o enfoque deste estudo reside em analisar discursivamente, a partir de comentários publicados num grupo de bolsistas de uma agência de fomento no Facebook, como se constrói representações acerca do trabalho na pós-graduação na atualidade, a partir de relações de saber-poder. $\mathrm{O}$ grupo é formado majoritariamente por discentes e egressos que foram bolsistas em programas de pós-graduação, bem como alunos da iniciação cientifica. Possui mais de 60 mil membros e as postagens publicadas são avaliadas por um serviço de moderação que pode aprová-las ou não. Os dizeres que circulam no grupo são variados, desde memes e vídeos de teor 
humorístico, passando por notícias que dizem respeito à docência e à pesquisa, até depoimentos de discentes acerca dos rumos de estudos individuais e dos planos para o futuro, dos conflitos com a orientação e/ou com o programa, bem como toda sorte de pedidos, seja auxílio financeiro ou de dúvidas em relação aos trâmites burocráticos que envolvem a pós-graduação.

Pensamos que, na conjuntura hodierna, será possível especificar as desventuras que matizam o trabalho na pós-graduação stricto sensu, haja a vista o cenário de descontinuidade política e governamental em relação ao incentivo à pesquisa. Conforme Ribeiro (2016), desde 2015, a Capes tem sofrido cortes drásticos no tocante aos recursos financeiros e, se pensarmos com Lopes (2019), que o capital humano é essencial para a expansão da ciência, poderemos demonstrar como esse estado de coisas reflete nas condições objetivas e subjetivas do trabalho na pós-graduação, as quais podem ser evidenciadas, quando os pesquisadores falam francamente sobre si nas redes sociais, espécie de ágora contemporânea onde o debate ocorre de modo frequente.

Para subsidiar o olhar investigativo, buscamos subsídio na perspectiva teórico-metodológica de Michel Foucault, por meio de noções como discurso, enunciado, prática discursiva, saber e poder. Considerando a academia como uma instância privilegiada de poder, interessa ponderar como os sujeitos nela inseridos constroem suas trajetórias de pesquisa e emolduram representações para si mesmo e para o outro.

Em relação à metodologia, este estudo segue um viés do método arquegenealógico, dado que busca, sob o olhar de Foucault, perscrutar arqueologicamente a formação dos saberes os quais engendram os discursos na interface das relações de poder genealogicamente vindas à lume por meio da história e das vontades de verdade. O corpus recobre a análise de dez comentários produzidos em razão de uma postagem publicada no mês de agosto de 2020.

No que se reporta à questão estrutural, dividimos este texto nas seguintes partes. Na seção a seguir, discutiremos alguns conceitos de Foucault relevantes para a análise desenvolvida. Posteriormente, tem-se o tópico que contém o exercício analítico do corpus, tomando como âncora as reflexões desenvolvidas anteriormente. Para finalizar, a última seção busca tecer determinados apontamentos de natureza conclusiva.

\section{SOBRE A ARQUEGENEALOGIA FOUCAULTIANA}

Michel Foucault foi um pensador que se debruçou sobre uma variedade de objetos de estudo em diferentes campos de saber, de maneira a desafiar as fronteiras disciplinares e os limites epistemológicos. Ainda que tenha falecido no florescer dos anos de 1980, a sua obra mostra-se cada dia 
mais atual, fazendo-nos pensar, sob as lentes foucaultianas, temas e questões da crítica do momento presente. Conforme Gregolin (2016), sobre o legado foucaultiano, saltam aos olhos a abrangência das temáticas, a solidez da argumentação e a transgressões à rigidez das balizes dos saberes. Pensar com Foucault, de acordo com Gregolin (2016), não redunda em simplesmente aplicar as teorias do autor francês num dado objeto de estudo, mas "[...] compreender a natureza fundante do conceito de discurso em seu pensamento e, a partir dessa fundação articular a rede conceitual que gravita em torno dessa centralidade da linguagem na produção de sentidos". (GREGOLIN, 2016, p. 3).

Essa centralidade do conceito de discurso comunga como o modo a partir do qual o pensador francês organizou seus estudos. Para Foucault (1995), o seu trabalho investigativo passeia por três momentos, a saber: a) arqueológico - o foco incide sobre a objetivação dos sujeitos a partir da análise dos saberes que fazem emergir as ciências humanas; ii) genealógico - a ênfase efetiva-se sobre a objetivação dos sujeitos através das relações de poder que promovam práticas divisoras como o normal e o anormal, os bons meninos e os deliquentes, dentre outras; iii) a ética e estética da existência - 0 interesse volve sobre as diversas técnicas por meio das quais o sujeito faz um trabalho sobre si mesmo, a partir de domínios como a sexualidade. Para encapsular essa divisão, Gregolin (2016) informa-nos que, conforme a leitura foucaultiana, o sujeito é fabricado por meio de três eixos de uma ontologia do presente, a saber: o ser-saber, o ser-poder e o ser-si. Isso porque, em Foucault (1995), somos levados a acreditar que o sujeito sempre foi o elemento nuclear sobre o qual os ditos e escritos do filósofo francês se debruçaram.

Considerando os limites deste estudo, fixaremos nosso horizonte investigativo no ser-saber e no ser-poder, de modo a investigar as relações de saber-poder na constituição discursiva do trabalho na pós-graduação. Para tanto, é necessário pensar, na esteira de Fischer (2013), como se configura uma análise dos discursos a partir dos postulados de Foucault. A priori, é importante registrar que esse autor nunca pretendeu elaborar uma disciplina ou corrente de estudos do discurso; contudo, as diversas ponderações do autor acerca do discurso e de conceitos adjacentes autorizam-nos a pensar, junto com ele, as bordas da Análise do Discurso de orientação francesa. Voltando a Fischer (2013), vemos que é necessário deixar de lado determinados equívocos quando se cogita fazer uma análise do discurso.

Segundo a autora, as principais impropriedades cometidas expressamse através das seguintes práticas: i) confundir discurso com fala e depoimento - as afirmações feitas oralmente devem ser tomadas como enunciações referentes a um certo tipo de discurso e não como o próprio discurso em si; ii) atrelar a análise do discurso a um procedimento de interpretação dos textos, 0 que implicaria achar um dado referente; iii) identificar, no fazer do analista, um movimento hermenêutico de buscar o que estaria por "trás" das coisas ditas, que verdade foi maquiavelicamente ocultada e, com isso, atribuir ao pesquisador a missão de descobrir a verdade escondida; iv) usar sem distinção o conceito de discurso com a noção de representação; v) analisar os discursos para, finalmente, chegar às coisas, como se estas estivessem desde sempre ocultas. 
Essas concepções limitadoras não encontram eco no modo como o discurso é concebido a partir de Foucault (2010). De acordo com o autor, o discurso é uma prática que constrói os objetos de que fala e é formado por enunciados que advêm de uma mesma formação discursiva. Portanto, o discurso não disfarça uma verdade, não se relaciona semanticamente com um referente exterior, mas liga-se ao conjunto das coisas que foram ditas, que foram efetivamente enunciadas numa conjuntura sócio-histórica específica. $O$ enunciado, de acordo com Foucault (2010), é o átomo do discurso, a unidade mínima de análise. Ao se distanciar de outros elementos como a frase, a proposição e 0 ato de fala, constitui uma função enunciativa que atravessa diferentes domínios e pertence exclusivamente aos signos.

Conforme Foucault (2010), o enunciado caracteriza-se pelas seguintes propriedades: i) referencial - não se constitui por fatos ou coisas, mas pelas leis de possibilidade que permitem emergir o enunciado; ii) posição de sujeito - mantém uma relação singular com o sujeito que enuncia, mas não se trata da primeira pessoal gramatical, do sujeito autor ou empírico, senão de uma posição que é assumida no enunciado; iii) domínio associado - diz respeito ao fato de o enunciado estar ligado a enunciados anteriores e aos que ainda serão produzidos, num encadeamento que, segundo Foucault (2010), forma um nó em uma rede; iv) materialidade repetível - refere-se a um suporte institucional, uma substância, uma data, um local através do qual o enunciado é dado a ver.

No intuito de descrever a função enunciativa, os postulados foucaultianos advogam que é preciso seguir alguns princípios, a saber; i) princípio da raridade - presume-se que o enunciado é raro no sentido de que se nem tudo pode ser dito numa dada circunstância história, o enunciado é singular no interior de um campo enunciativo; ii) princípio da exterioridade - o enunciado aparece no âmbito de uma dispersão e convém apreendê-lo num tempo e lugar específico, sem se apelar para uma subjetividade fundadora; iii) princípio do acúmulo - relaciona-se com as transformações que o enunciado sofre no decorrer do tempo, seja por meio de técnicas de conservação, seja por meio de elementos que compõem o campo enunciativo; iv) princípio da positividade - concerne ao que se chega quando se percorre todos os princípios anteriores.

Consoante Foucault (2010), o cumprimento desses princípios leva-nos à análise da formação discursiva, concebida como um conjunto de regularidades o qual pode ser flagrado a partir de certos objetos, conceitos, escolhas temáticas e tipos de enunciação. Já a prática discursiva imbrica-se a uma série de regras anônimas e históricas que permitem o exercício da função enunciativa. Nessa ciranda, entra em jogo o conceito de saber, entendido por Foucault (2010) com o que pode ser dito no interior de uma prática discursiva.

No âmbito dos estudos foucaultianos, há uma relação intrínseca entre o saber e o poder. Nas palavras do autor, "[...] não há relação de poder que sem constituição correlata de um espaço de saber, nem saber que não suponha e não constitua ao mesmo tempo relações de poder". (FOUCAULT, 1999, p. 27). O poder, nesse viés, é entendido por meio de uma microfísica mediante uma analítica que concebe as relações de poder através da dispersão, das estratégias e das lutas. Quer dizer, o poder se espraia por todo 
o corpo social, mas não é pautado por uma ótica totalizante, opressora e/ou dominadora. No ponto de vista foucaultiano, o poder não se encontra incrustado somente sob a figura do Estado ou da economia, mas atravessa uma miríade de práticas sociais nas quais sujeitos livres têm suas ações impactadas por relações de força, concebidas como móveis, fluidas e cambiantes. Isso significa dizer que, ao contrário de uma relação de violência, o poder não age imediatamente sobre o outro, mas considera a existência de um jogo entre parceiros. Para Foucault (1995), trata-se de dois polos em que os sujeitos são ativos e permite toda sorte de fugas, resistências e embates.

Em Foucault (1995), vemos que a análise das relações de poder demanda o estabelecimento de alguns pontos, a saber: i) sistema de diferenciações - permitem agir sobre a ação do outro, a partir de diferenças jurídicas, econômicas, habilidades e competências; ii) tipos de objetivos perseguidos - diz respeito às pretensões dos que agem sobre a ação dos outros e podem se manifestar através da continuidade de privilégios, concentração de lucros e vantagens, operacionalidade da autoridade e exercício de uma função ou profissão; iii) modalidades instrumentais relaciona-se com as aparelhagens responsáveis por mediar as relações de poder, as quais podem se apresentar sob a forma de armas, efeitos da palavra, desigualdades econômicas, sistemas de vigilância, dentre outros iv) formas de institucionalização - atrelam-se a dispositivos tradicionais, estruturas jurídicas e práticas de hábito ou de moda; v) graus de racionalização - o funcionamento das relações de poder pode ser mais ou menos eficaz a depender da relação existente entre o desempenho dos instrumentos demandados e o cálculo dos resultados a serem alcançados.

Vemos nesta seção alguns conceitos da teoria foucaultiana que podem ser mobilizados para examinar discursivamente fenômenos da atualidade. Assim, o olhar arquegenealógico possibilita entrever o funcionamento dos saberes que compõem os discursos no cotejo com as relações de poder historicamente emolduradas. A centralidade do discurso é ratificada por Sargentini (2014, p. 163), ao defender que "[...] o discurso se apresentou como o centro desencadeador de suas análises [de Foucault], uma vez que compreendia que o objeto de pesquisa de sua materialidade não pode ser compreendido separado dos quadros formais por meio do quais 0 conhecemos: a saber, o discurso".

\section{DESVENTURAS DO TRABALHO NA PÓS-GRADUAÇÃO: EXERCícIO ANALÍTICO}

Antes de iniciarmos a análise propriamente dita, é cabível pontuarmos acerca dos deslocamentos em torno da ideia de trabalho. Consoante nos informam Neves et al (2018), a noção de trabalho muda ao sabor das contingências sócio-históricas e das transformações tecnológicas que redefinem as relações de trabalho e a identidade do sujeito trabalhador. De acordo com os autores, o trabalho é compreendido sob diferentes vieses porque constitui uma prática multifacetada, polissêmica e heterogênea. Nessa 
ótica, fulguram-se diferentes sentidos, seja de redenção e nobreza ou de expropriação e martírio. Consoante Oliveira e Silveira (2012), a palavra trabalho é eivada por uma discursividade bíblica que a atrela ao martírio e à punição. Além disso, segundo as autoras, a etimologia de trabalho carrega consigo essa conotação, porquanto remete "[...] ao substantivo tripalium (instrumento feito de três paus aguçados, com ponta de ferro, com o qual os antigos agricultores batiam os cereais para processá-lo) e o verbo tripuliare, igualmente do latim vulgar, que significa "torturar sobre o tripalium". (OLIVEIRA; SILVEIRA, 2012, p. 150).

No atual momento histórico, profundamente assinalado por um viés neoliberal, o trabalho é perpassado pelo mantra da flexibilidade, do uso das tecnologias digitais, da redução de direitos historicamente conquistados. A sociedade de controle, conforme propugnada por Deleuze (2006), incide decisivamente nas relações trabalhistas, tendo em vista a entronização do modelo empresarial que, diferentemente do paradigma fabril, estabelece uma certa descontinuidade na produção e, portanto, engendra novos agenciamentos para o sujeito trabalhador. Nas palavras de Neves et al (2018, p. 320), muito se debate sobre as configurações do trabalho na contemporaneidade, "[...] sobretudo daqueles concernentes/decorrentes da introdução de novas tecnologias de produção, tais como a informatização, a automação, os novos modelos de gestão e as novas possibilidades de produtividade".

Como corolário dessa dinâmica de atendimento às normas de mercado, produz-se a formação do chamado precariado, ou seja, uma legião de sujeitos que podem possuir uma determinada formação, mas que não encontra oportunidades de trabalho compatíveis com essa formação e precisam se submeter a uma miríade de ocupações ou não assumir qualquer tipo de função, seja formal ou informal. Para Veiga-Neto (2018, p 43), na racionalidade neoliberal, a competitividade é uma peça central e, sob essa lógica, "[...] nem todos são conduzidos de uma mesma maneira ou se submetem a uma condição comum, e nem a todos são dadas oportunidades de uma mesma condição". Certamente essas questões aparecerem com mais ênfase nos comentários sobre os quais lançaremos nosso olhar investigativo, a seguir.

Comecemos a análise, mostrando a postagem do grupo de bolsistas no Facebook responsável por fazer emergir os comentários que compõem as materialidades discursivas do corpus. Em tal postagem, um discente da graduação, bolsista de Iniciação Científica (IC), busca maiores informações sobre a pós-graduação, levando em consideração dizeres inscritos em outros comentários publicados no grupo. Vejamos alguns enunciados da postagem.

Tô com a pulga atrás da orelha. 
Gente, eu tô entendendo errado ou na vida acadêmica a pessoa estuda 8-10 anos pra ficar desempregada ou receber um salário baixo (é o que eu mais vejo nos comentários de outras postagens)?

Desculpem a desinformação, mas sou novo na área, ainda estou na IC e tenho essa dúvida a um tempo já.

$[\ldots]$

Realmente vale a pena dedicar quase $1 / 3$ da vida adulta sem emprego, com pressão psicológica e infeliz tanto financeiramente quanto psicologicamente (novamente, é o que mais vejo nos comentários).

Impressão minha ou os acadêmicos são pessoas muito aplicadas mas que não são valorizadas e apenas trabalham como acadêmicos porque amam?

Me ajudem com isso. Estou pensando em entrar no mestrado (área da saúde), mas vejo mais pontos negativos do que positivos aqui nos comentários.

A posição que enuncia parte de umas hipóteses que podem convencêlo a seguir ou não na vida acadêmica, mais especificamente o ingresso na pósgraduação. Assim, ao mesmo tempo que apresenta, num domínio associado, enunciados já produzidos acerca do trabalho na pós-graduação, o sujeito enunciador busca conselhos dos membros do grupo, concebidos discursivamente como situados em lugares do esclarecimento, pois teriam experiências de vida para sanar as dúvidas que afligem o bolsista da IC. Ao indagar "estou entendendo errado [...]?", esse posicionamento discursivo especula que subsiste uma dada representação acerca do trabalho na pósgraduação, pautada tanto em questões de ordem objetiva, como subjetiva, ou seja, em relação às condições de trabalho e à construção identitária do pesquisador. Essa racionalidade irá nortear as posições presentes na materialidade repetível dos comentários da postagem, pois, tem-se, por um lado, a romantização de dizeres segundo os quais o pesquisador faz o seu trabalho "por amor", por outro, a constatação de que esse trabalho gera danos de ordem diversas, principalmente financeiras e psicológicas, tendo em vista a relação entre custo e benefício, mais precisamente o dispêndio de tempo exigido pela pesquisa ("estuda 8-10 anos") e a falta de um retorno direto de tal esforço ("ficar desempregada ou receber um salário baixo").

Nesse sentido, com vistas a responder ao questionamento feito na postagem, foram publicados cerca de duzentos comentários. Para este estudo, selecionamos dez deles. Por uma opção metodológica, não revelaremos o nome dos sujeitos que escreveram os comentários, porquanto, importa-nos, segundo a orientação da análise foucaultiana, perceber a posição que enuncia não a partir do sujeito empírico ou autor das postagens, senão a posição 
assumida num dado discurso. Codificamos, portanto, os comentários a partir da ordem em que aparecem na publicação (de 1 a 10) e mantivemos a escrita do modo como aparece nas redes sociais.

Assim, os comentários, de um modo geral, exprimem sentidos a partir dos quais o trabalho na pós-graduação é emoldurado como uma atividade que não rende no paradigma neoliberal, marcado pela produtividade e imediatismo nas relações com o mercado, bem como no contexto mais específico do Brasil nos últimos anos, a partir da explícita desvalorização da pesquisa e do trabalho do pesquisador. Desse modo, uma regularidade presente nos discursos corporifica-se num tom de lamento por parte de sujeitos que dedicaram anos de suas vidas e ainda não obtiveram ou acham que vão obter o retorno desejado, em termos de estabilidade financeira, conforme se observa em "Doido pro mestrado acabar e voltar pro mercado formal, eu era ótimo no que fazia" (Comentário 1), "Pesquisa no Brasil é igual a docência, você por amor e não por dinheiro" (Comentário 2), "Se eu pudesse voltar atrás, não teria feito mestrado, nem doutorado...frustrante...desanimante...se tiver outra opção, se joga" (Comentário 3).

Vejamos, nos três primeiros comentários, que há um efeito de desencanto no discurso desses posicionamentos enunciativos. O primeiro destaca a sua insatisfação em relação à pós-graduação, por meio do desejo que o curso acabe logo, a fim de retornar ao mercado; o segundo enuncia, a partir de uma comparação com a docência, pois a relação entre o "amor" à pesquisa é correlata do "amor" à docência, à revelia de gratificações financeiras. De acordo com Uyeno (2014), chama a atenção certos discursos de professores que não fazem eco ao tom queixoso, propalado pelo cenário desolador das condições de trabalho docente. Esses discursos parecem apelar para a necessidade de recompensar a ausência de valorização da profissão sob o prisma do comprometimento individual a partir de uma missão pautada pelo amor à docência. O terceiro comentário confessa o arrependimento em ter feito cursos de mestrado e doutorado e aconselha o aluno da IC buscar outra opção, a qual seria mais proveitosa que a inserção na pós-graduação. $\mathrm{Na}$ emergência desses enunciados, a exterioridade de que fala Foucault (2010) mostra-se a partir das leis que fazem emergir esses dizeres no esteio de uma singularidade. Noutros termos, a partir do avanço da pós-graduação no Brasil e as mudanças instáveis do mercado e a consequente desvalorização da pesquisa levam a produção de discursos que sinalizam para um esgotamento e/ou saturação dessas políticas de formação. Nos comentários, o uso de termos como "atualmente", "na situação atual", "hoje no Brasil", dentre outros, assinalam a temporalidade o exercício dessa função enunciativa. Como efeito, valoram-se certas percepções segundo as quais a pós-graduação não deve ser o único plano de carreira e que é preciso criar outras alternativas de trabalho e renda. 
Nessa medida, enunciados como "Minha sugestão é se dedicar a outra coisa também. Algo que dê dinheiro mais rápido" (Comentário 4), "Mestrado e doutorado no Brasil é morrer na praia" (Comentário 5), "Infelizmente, na situação atual eu não indicaria ninguém a se dedicar integralmente para apenas uma possibilidade. Faça IC e, se possível, estágio na sua área" (Comentário 6) aparecem com recorrência. Observamos que esses dizeres ratificam a urgência em ter um plano suplementar, dado o risco iminente de malogro na carreira de pesquisador. É preciso investir em algo que dê um retorno mais urgente, podendo, pois, constituir uma possibilidade de êxito para além da pesquisa. Para isso, há o aconselhamento de que se faça pesquisa e, de modo concomitante, estágio. O quinto comentário adota um tom fatalista ao asseverar que a pós-graduação stricto sensu no cenário brasileiro não constitui uma garantia de êxito profissional. Esses posicionamentos constituem saberes, os quais, conforme compreende Foucault (1999), estão conectados com relações de poder. De modo mais específico, constroem-se saberes que apontam para um quadro prospectivo desolador para a pós-graduação e, por conseguinte, irrompem posicionamentos atrelados a relações de poder que regulam como se deve agir: buscar outras alternativas, não ingressar na pós, ou, em caso de ingresso, conciliar com demais possibilidades.

Em todo o caso, podemos constatar a existência de representações acerca do trabalho na pós-graduação como uma atividade para a qual é preciso ter prudência e que não vale a pena investir, se levar em conta pretensões mais urgentes de remunerações compatíveis com a formação alcançada. Nos comentários a seguir, é visível o efeito de insatisfação dos sujeitos pesquisadores em relação aos desdobramentos relacionados às experiências na academia, especificamente na pós-graduação.

Eu fiz doutorado, por ideal sonho em ajudar meu país e contribuir um pouquinho em nossa sociedade. Mas de fato só faça mesmo por ideal. Caso contrário corra. A vida acadêmica me ajudou no aspecto pessoal, conheci muita gente do bem, melhorei como pessoa. Mas profissionalmente não me ajudou em nada. Me atrasou muito. Hoje com 35 e mãe preciso mesmo é de um contrato CLT, convênios e benefícios. [...] Sinceramente acredito que só vale a pena se VC tem una família que possa te manter no futuro e se é um sonho, caso contrário não continue. (Comentário 7)

Sou mestre em Engenharia e diga uma coisa: nesse Brasil não vale a pena se dedicar a vida acadêmica. Dei maior duro horas e horas estudando na graduação e no mestrado e até agora não fui recompensado financeiramente pelo meu esforço ( estou atualmente desempregado ). A única coisa que pode lhe dar renda é concurso publico. Hoje em dia eu não aconselho jovens de classe baixa a entrar nas universidades ( a não ser 
que vc faça medicina ) por que custo - benefício não compensa. Faça concurso que é melhor. (Comentário 8).

Antes de entrar na pós, você precisa avaliar quais são seus objetivos de vida e considerar que todo o período da pós é extremamente desgastante (nem se compara com a IC, eu gostaria que tivessem enfatizado isso pra mim) e o reconhecimento praticamente não existe. Começar mestrado e doutorado simplesmente porque é o caminho natural nas federais ou porque não conseguiu emprego de imediato é tiro no pé. Pense bem e boa sorte :) (Comentário 9).

Os posicionamentos dos enunciados dispostos, especialmente 0 sétimo e oitavo, são construídos através da experiência de sujeitos que fizeram a pós-graduação e avaliam seus percursos formativos, de modo a apontar que, a despeito de a experiência estar atrelada a vínculos pessoais e sociais fortalecidos nos cursos, a profissionalização é um fator ausente e a precarização do trabalho mostra-se constante, haja vista a inexistência de direitos ou garantias. No comentário 7, a ênfase na idade e nas condições socioeconômicas de uma doutora realça a posição sujeito para quem o tempo dispendido à pós-graduação representa o cumprimento de um desejo pessoal ou um papel social assinalado pela menção à cidadania ("ideal sonho em ajudar meu país") e não atesta a empregabilidade. A referência à formação do sujeito que enuncia, no comentário 8 ("Sou mestre em Engenharia"), serve para elucidar o seu dizer, pois, conforme esse posicionamento, o esforço empregado na academia ("duro horas horas") não resultou em nenhum tipo de compensação financeira. Esses saberes, advindos da prática, levam esses sujeitos a não recomendarem outros que estejam interessados em trilhar o percurso por eles empreendidos. No comentário 9, o sujeito é enfático em recomendar que é cabível avaliar, de modo preciso, os interesses de cada um, porquanto seguir o curso da pesquisa que começa na IC ou porque não há oportunidades de trabalho é um caminho fadado ao insucesso ("tiro no pé"). Convém destacar ainda o fato de o sujeito confessar que gostaria de ter sido alertado acerca dos riscos relativos às escolhas empreendidas.

Em linhas gerais, vemos que o saber sobre o qual os comentários se amparam reside na incerteza de ganhos financeiros resultantes dos esforços demandados para a pós-graduação. Nesse sentido, é possível entrever um discurso de cautela em relação à inserção na pós-graduação. No comentário 7, esse discurso está alinhado à experiência do sujeito enunciador que, ao falar de um lugar do esclarecimento, constitui um exemplo de insucesso financeiro; no comentário 8, o posicionamento é semelhante e há um expressivo aconselhamento em relação à necessidade buscar um concurso público e no comentário seguinte aparece dizeres que corroboram o fato de o momento posterior ao término de cursos de pós-graduação ser corrosivo. Atravessando esses três comentários, vê-se o funcionamento de relações de poder que 
incidem sobre a ação de outros sujeitos, conforme apontado por Foucault (1995). Essas ações, segundo esses discursos, consistem em ponderar tenazmente se vale a pena o investimento de tempo e esforço na pósgraduação, tentar um concurso público como a alternativa mais viável em termos de remuneração e só fazer pós-graduação se for um desejo pessoal destituído de ambições financeiras imediatas. É imperioso destacar que todos os comentários em análise constituem uma resposta à publicação de um jovem que observa o cenário da pós-graduação e pede conselhos sobre qual caminho trilhar. Por isso, os enunciados são constitutivamente marcados por dicas, conselhos, opiniões e pareceres.

Entendemos, a partir da análise, que o trabalho na pós-graduação é racionalizado pela lógica da produção capitalista cujo interesse central é o lucro e o acúmulo de renda. Nessa visada, é preciso avaliar os custos e os benefícios do ingresso na pós-graduação quando se pensa na construção da carreira. De acordo com Charlot (2019), na atualidade os jovens estão imersos numa grande corrida escolar, norteada por uma lógica neoliberal que prima pela competividade. Desde cedo, os pais, ao se preocuparem com o futuro dos filhos, pensam no emprego que eles irão conseguir e, para isso, precisam ser ordenados num ranking excludente por natureza. Essa busca pela carreira bem-sucedida assinala a indagação da publicação que origina os comentários no grupo do Facebook, dentre os quais encontram lugar para reflexões como "Olha. Eu me pergunto essas coisas todos os dias há 10 anos. Rs. Rindo, mas na verdade chorando" (Comentário 10). Nesse enunciado, fica em evidência a persistência do sujeito no contexto da pós-graduação, marcada pela referência ao tempo, e a partilha de uma preocupação semelhante a postulada pela publicação no grupo.

\section{CONSIDERAÇÕES FINAIS}

Coincidentemente (ou não!) durante o percurso de escrita desse texto, deparamo-nos em redes sociais com duas publicações cujos links nos levavam para reportagens que acentuam o cenário apontado pelos comentários analisados. A primeira publicação nos guiou para o site da $\mathrm{Uol}$, especificamente a um texto intitulado Cientistas em fuga: forçados a deixar o país por oportunidades, eles refletem sobre a carreira no exterior e o futuro do Brasil. A segunda referia-se a reportagem assim denominada, Fuga de cérebros: os doutores que preferiram deixar o Brasil para continuar pesquisas em outro país, publicada no site da BCC Brasil. A regularidade a entrecortar os enunciados dessas materialidades jornalísticas reside na constatação segundo a qual há uma crescente precarização do trabalho do cientista no país, fator responsável por desencadear a saída progressiva de pesquisadores brasileiros. Conforme anunciamos no início deste texto, as condições políticas 
e econômicas vivenciadas no Brasil hoje arrefecem a descaracterização da ciência, especialmente quando pensamos na guerra cultural levada a cabo pelo espectro político que assumiu o país a partir da eleição de 2018. Basta lembrarmos da famosa "balbúrdia" que o ex-ministro da Educação Abraham Weintraub imputou às universidades federais como "punição" para o contingenciamento de recursos financeiros, em 2019.

Com a ciência e o trabalho acadêmico em franco descrédito pelas autoridades públicas, torna-se cada dia mais difícil persistir com a pesquisa no país. Nessa conjuntura, os comentários estudados neste texto permitem entrever como se constroem representações acerca do trabalho na pósgraduação, a partir de posicionamentos de quem vivencia ou vivenciou a experiência acadêmica e, com isso, produz um dizer verdadeiro acerca dessa questão. Visamos investigar neste texto como tais representações se aliam a relações de saber e poder, tendo como bússola os estudos discursivos de Foucault.

Foi possível identificar que o trabalho na pós-graduação, levando em conta as idiossincrasias no momento presente, é conceptualizado como uma atividade para a qual não há quaisquer garantias de conquistas financeiras imediatas. Os relatos corporificados nos comentários são dotados por uma atmosfera confessional cujos efeitos são relacionados ao arrependimento de ter feito pós-graduação, à descrença em relação aos rumos do país, ao aconselhamento de que se, possível, é preciso buscar outras alternativas e não investir integralmente na pesquisa. Embora, em algumas passagens, haja a remissão a alguns benefícios da pós-graduação no âmbito da formação interpessoal, o que se constata é a recorrência de posicionamentos discursivos fundidos em saberes a defender a improdutividade do tempo dispendido à pósgraduação e a ausência de um retorno financeiro compatível com o esforço demandado. Resultantes de tais saberes, irrompem relações de poder que se voltam para a construção de ações as quais sinalizam para o afastamento dos jovens desse nível educacional e o investimento em outras possibilidades de constituição da carreira.

\section{REFERÊNCIAS}

BRASIL. Comissão Especial de Acompanhamento do PNPG (2011-2020): relatório de 2019. Capes: Brasília, 2019. Disponível em:

<https://www.capes.gov.br/images/novo_portal/documentos/PNPG/25052020

Relat\%C3\%B3rio_Final_2019_Comiss\%C3\%A3o_PNPG.pdf>. Acesso em: 09 set. 2020.

CHARLOT, Bernard. A questão antropológica na educação quando a barbárie está de volta, Edu. rev., Curitiba, v. 35, n.73, jan./fev. 2019. Disponível em: 
<http://www.scielo.br/scielo.php?script=sci_arttext\&pid=S0104-

$40602019000100161 \&$ Ing=pt\&nrm=iso\&tlng=pt>. Acesso em: 20 jul. 2019.

DELEUZE, Gilles. Pós-scriputm sobre as sociedades de controle. In:

DELEUZE, G. Conversações. Trad. Peter Pál Pelbart. São Paulo: Editora 34, p. 219-226, 2006.

FOUCAULT, Michel. O sujeito e o poder. In: RABINOW, P.; DREYFUS, H. Foucault: uma trajetória filosófica para além do estruturalismo e da hermenêutica. Trad. Vera Porto Carrero. Rio de Janeiro: Forense Universitária, 1995, p. 231-250.

FOUCAULT, Michel. Vigiar e punir: nascimento da prisão. Trad. Raquel Ramalhete. Petrópolis: Vozes, 1999.

FOUCAULT, Michel. A arqueologia do saber. Trad. Luiz Neves. Rio de Janeiro: Forense Universitária, 2010.

FISCHER, Rosa Maria Bueno. Foucault. In: OLIVEIRA, L. A. (Org.). Estudos do discurso: perspectivas teóricas. São Paulo: Parábola, 2013, p. 123-151.

FREITAS, Maria de Fátima Quintal de; SOUZA, Jusamara. Pensar a formação e a pesquisa na pós-graduação strictu sensu, Educ. rev.., v. 34, n. 41, set./out. 2018. Disponível em: <https://www.scielo.br/pdf/er/v34n71/01044060-er-34-71-9.pdf>. Acesso em: 03 set. 2020.

GREGOLIN, Mario do Rosário. Michel Foucault: uma teoria crítica que entrelaça o discurso, a verdade e a subjetividade. In: FERREIRA, Ruberval; RAJAGOPALAN, Kanavillil. (Orgs.). Um Mapa da Crítica nos Estudos da Linguagem e do Discurso. Campinas: Pontes, 2016, v. 1, p. 115-142.

GARCIA, Janaina. Cientistas em fuga: forçados a deixar o país por oportunidades, eles refletem sobre a carreira no exterior e o futuro do Brasil, Uol, 2020. Disponível em: <https://www.uol.com.br/ecoa/reportagensespeciais/cientistas-que-deixaram-o-pais-refletem-sobre-a-carreira-noexterior-e-o-futuro-do-brasil/index.htm\#cover>.

KIPNIS, Bernardo; CARVALHO, Olgamir Francisco. O Plano Nacional de Pós-Graduação PNPG (2005-2010), a formação de gestores para a Rede de Educação Profissional e Tecnológica e as tecnologias da informação e comunicação (TIC): a experiência do Projeto Gestor, Revista Brasileira de Educação Profissional e Tecnológica, Mossoró, v.1, n.1, p. 55-68, 2018. Disponível em: http://www2.ifrn.edu.br/ojs/index.php/RBEPT/article/view/2869. Acesso em: 08 set. 2020.

LOPES, Cristiano Aguiar. Pós-graduação stricto sensu no Brasil e produção científica do Brasil. Consultoria Legislativa da Câmara dos Deputados: Brasília, 2019. Disponível em: 
$<$ https://bd.camara.leg.br/bd/handle/bdcamara/39019>. Acesso em: 05 set. 2020.

OLIVEIRA, Maria do Carmo Leite de; SILVEIRA, Sonia Bittencourt. O(s) sentido(s) do trabalho na contemporaneidade, Veredas, Juiz de Fora, v.1, p. 149-165, 2012. Disponível em:

<https://www.ufjf.br/revistaveredas/files/2012/10/artigo-Sonia-e-

Carmovers\%C3\%A3o-finalformatado.pdf>. Acesso em: 14 set. 2020.

NASCIMENTO, Antônio Dias do. Formação em pesquisa na pós-graduação: práticas e desafios. A formação do pesquisador em Educação na Universidade Federal da Bahia, Educ. rev. Curitiba, v. 34, n. 41, set./out. 2018. Disponível em: <https://www.scielo.br/scielo.php?pid=S010440602018000500019\&script=sci_arttext>. Acesso em: 04 set. 2020.

NEVES, Diana Rebello et al. Sentido e significado do trabalho: uma análise dos artigos publicados em periódicos associados à Scientific Periodicals Electronic Library. Cad. EBAPE.BR, Rio de Janeiro, v.16, n.2, p.318-330, 2018.

RIBEIRO, Daniella Borges. Os Planos Nacionais de Pós-Graduação: qual direção dada à produção de conhecimentos no Brasil, Revista Libertas, Juiz de Fora, v. 16, n. 2, jul./dez. 2016. Disponível em:

<https://periodicos.ufjf.br/index.php/libertas/article/view/18440>. Acesso em: 10 set. 2020.

SILVEIRA, Evanildo. Fuga de cérebros: os doutores que preferiram deixar o Brasil para continuar pesquisas em outro país, BBC Brasil. 2020. Disponível em: <https://www.bbc.com/portuguese/brasil-

51110626? fbclid=IwAR2JdTxYz5pqA2h0BfU8dnqx1sNMTBRbfTotUOMnAax1 kAFflHBNiB6s7Jk>. Acesso em: 12 set. 2020.

VEIGA-NETO, Alfredo. Neoliberalismo e educação: os desafios do precariado. In: RESENDE, Haroldo de. (Org.). Michel Foucault: a arte neoliberal de governar e a educação. São Paulo: Intermeios, 2018, p. 77-94.

UYENO, Elzira Yoko. O desafio da docência na (pós)modernidade: o "novo amor" e a responsabilização pedagógicos. In: CORACINI, Maria José; CARMAGNAMI, Anna Maria G. (Orgs.). Mídia, exclusão e ensino: dilemas e desafios da contemporaneidade. Campinas: Pontes, 2014, p. 251-278. 
ISSN - 2447-1801

REVISTABRASILEIRA

DA EDUCACÁO PROFISSIONAL E TECNOLOGICA

Vol. 2 (2020) 